\title{
Transduction and BRICS
}

\section{Don Peterson}

\section{Shantou University}

Department of Computer Science

Da Xue Lu, 243, Guangdong, 515063, China.

中国广东省汕头市大学路243号汕头大学计算机系 | 邮编：515063

peterson@stu.edu.cn

Received: 17.01.2015; Revised: 22.10.2015; Accepted: 30.12.2015

DOI: http://dx.doi.org/10.1590/0100-6045.2015.V38N3.DP

\begin{abstract}
BRICS has philosophical significance. It creates new pressure on cross-cultural skill. This is analysed here as requiring transduction: a variety of defeasible practical reasoning. This replaces a simplistic model of the relation between knowledge and action with a more realistic and contemporary model. The transduction format has utility in cross-cultural training.
\end{abstract}

Keywords: BRICS; cross-cultural skill; context; executive function; schema theory.

\section{BRICS}

BRICS is a collaboration between Brazil, Russia, India, China, and South Africa: it was identified as a possibility by O'Neill (2001), official discussion began in New York in 2006, and the bloc was formally initiated in Yekaterinburg in 2009. Since 2010, the BRICS nations have met annually at formal summits. Bilateral relations among BRICS nations emphasise mutual 'win-win' benefit, non-interference, and equality.

There are other blocs: ASEAN (Association of Southeast Asian Nations), initiated in 1967, now includes Indonesia, Malaysia, the Philippines, Singapore, Thailand, Brunei, Cambodia, Laos, Myanmar, and Vietnam. O'Neill, who first identified BRICS, has identified: MIKT (Mexico, Indonesia, South Korea, and Turkey), MINT (Mexico, Indonesia, Nigeria, and Turkey), and the 
Next Eleven (Bangladesh, Egypt, Indonesia, Iran, Mexico, Nigeria, Pakistan, the Philippines, Turkey, South Korea, and Vietnam).

These blocs are, of course, an issue for economics and politics (Gutemberg, 2015). They are also an issue and direction for contemporary philosophy. The world has changed, life has changed, and the challenge to our cognitive apparatus has changed. There may be 'nothing new under the sun', but the need to interact and collaborate with 'the other' is greater now than before. In the past, of course, some people needed to interact internationally, but the obligation is greater now. The modern condition in the 21 st Century is one of cooperating heterogeneity, in which we keep our differences, but we have to collaborate. In the past, we had our differences (in culture, language, religion, cuisine, legal systems, business practice, art, etc.) but we could ignore each other, or not take each other seriously, even under colonialism. In the present, we have our differences but we cannot ignore each other. There has occurred, in fact, a sea change in the demands on human cognition. This may be a change in degree rather than principle, but it is a sea change.

The emergence of blocs such as BRICS makes two things clear in the problematic of the philosophy of globalisation. The first is that we will not homogenise. We will not acquire one unified world system of politics, religion, culture, law, ethics, cuisine, language, art, etc. These blocs are collaborations, they are not melting pots. The second is that we have to collaborate. Ignoring other cultures is no longer an option. Disrespecting other cultures is no longer an option. International business and multinational companies have become a norm rather than an exception.

Accordingly, a service industry in cross-cultural skill has arisen, and is growing fast. In international business, management, and human resources management, cross-cultural skill is now seen as crucial. The field is new, and several names are currently in use: 'cross-cultural' may become 'inter-cultural', 'skill' may become 'communication', 'competence', or 'capability', etc. Countries such as those in BRICS need to do business with each other on a routine basis. Collaboration is essential. Multinational teams are normal (Halverson and Tirmizi, 2008). Expatriate failure is expensive (Chew, 2004). As a live area of applied psychology, support for cross-cultural skill is now supplied worldwide in the forms of training, consultancy, and psychometric testing (Livermore, 2015; Hofstede and Minkov, 2010; Ang and Van Dyne, 2008). 


\section{TRANSDUCTION and BRICS17}

A key point here is that what we need to achieve is win-win collaboration. We do not have to become the other, be like the other, agree with the other, nor like everything about the other. In fact, collaboration may be best if we retain our difference. Retaining our difference, we may have more to offer each other. This casts a sceptical philosophical light on some 'dead' metaphors. We talk of 'seeing' the other's point of view, 'knowing' their culture, putting ourselves 'in their shoes', and so on. Is this helpful? Is this accurate? The actual objective is synergy. The Greek etymology of the word 'syn-ergy' is 'together-work', and this is the point. Under BRICS, under the other blocs, under cooperating heterogeneity, we need to do this. In short, the main issue is action. We need to do the right thing, and avoid doing the wrong thing, in complex situations.

Of course, knowledge matters. We need to know etiquette. We need to know that the other culture likes this and does not like that. Even better, we know their history and some reasons for their preferences. Even better, we grow to appreciate some of their gems, such as Brazilian dance, Russian bass, Indian yoga, Chinese tea, or South African music. But knowledge is not enough. We need adaptive action. At home, we might do one thing. In our own culture, we might do things a certain way. But in a trans-national working situation we may not have this simple option. We may need to adjust to the additional factor of the other culture. This is inherently more complex than operating within our own culture, but it is a feature of modern life under BRICS and other blocs, where it is now clear that we will not homogenise, and we must collaborate.

The issue of adaptive action is therefore prioritised in the modern age. The basic task is to retain our integrity while working with the other. As is well known, expatriate maturity involves a conjunction of these two factors. Progress in this is illustrated as a U-curve moving through initial elation, culture shock, and then differentiated adjustment (Adler and Gundersen, 2007). Of course, we acquire knowledge of the other culture as we progress. Of course this may be enlightening, and we may change as a result. But in the end intercultural business relationships are collaborative rather than synthetic. We do not really become a member of the other culture, but we create productive synergy with members of the other culture.

We now introduce the concept of transduction as an analysis of adaptive action. This does not pretend to solve all the problems of the modern 
age. But it is a topic of contemporary relevance, which merits analysis.

\section{Transduction}

We turn first to the human brain. We turn to the basic equipment which we have. Work in neuropsychology on 'executive function' has established that our performance (behaviour, action) results from two factors, not one. Our performance results from a combination of knowledge (in the form of schemas) and executive function (control over the enactment of schemas) (Elliott, 2003). Piaget (1952) defined a schema as 'a cohesive, repeatable action sequence possessing component actions that are tightly interconnected and governed by a core meaning'. Schemas are rule-of-thumb formulae for action in standard situations. They tell us what to do normally, all things being equal.

The first challenge here is that we need to select which schema to activate at any given time. We cannot do everything at once, and a juggling act is needed. We need to control when we start, when we stop, and when we temporarily suspend our schemas. Norman and Shallice (1986) attribute this function to 'contention scheduling'. This capability is associated with the prefrontal cortex. This area is at the top, and at the front of the human brain. This is thought to be only an association: executive function relies also on other areas of the brain, and this area of the brain does other things too (Alverez et al, 2006). Nevertheless, it is a strong association.

The second challenge is that, having selected a schema, we may need to modulate its enactment. In standard, routine situations, we may not need to do this, but in novel situations, we may need to produce adjusted action. We may need to adjust how, where, when, and with whom we do things and say things, which may be crucial to success. Norman and Shallice recognise this as a function of the 'Supervisory Attention System' (SAS). The point for BRICS and the age of globalisation, is that 'novel' situations have become normal in international business. This is not a challenge which happens once a year. It is a challenge which happens every day. We rely on standard schemas, formulae, principles, and routines: but we also need to steer their enactment. We need to steer the detail of how we do what we do, in response to the other party, the other culture. 
Transduction is a form of adjusted action. In neuropsychology, this is the second function identified by Norman and Shallice. In logic, it is a form of defeasible practical reasoning (reasoning to a conclusion on action, which is influenced by context which can change our decision).

We start with an example.

[E1] You have a standard route to work. This includes walking down a particular pavement. Today, however, you see a big puddle of water covering the width of the pavement. So on this occasion, you stop, walk round on the road, and continue after the puddle. Your feet stay dry, and nothing is disturbed. (Tomorrow, you find no puddle, and you return to your usual enactment.)

We see here a pattern of four components:

[S] A basic schema, which generates standard or routine action.

[D] A default action, which would normally be performed, in the absence of anything to the contrary.

[C] A context, comprising circumstances relevant to the consequences of our performed action.

[V] A variant action, this being a version of [D] whose details of enactment are adjusted to [C].

This is a basic case, but it reveals a reasoning format which is often required. We now consider a cross-cultural example.

[E2] A group of long-term resident expatriates in Dubai planned to visit a museum at $2.00 \mathrm{pm}$ on a Wednesday. The sign on the museum wall says that it is open at this time. On arrival, they find that the door is shut, and a man comes out and tells them to go away and come back later. The expatriates become angry. They do in fact have the necessary knowledge. They know that this is the month of Ramadan, which involves extra and obligatory prayer times for Muslims, which take priority over work. It takes them some time to engage this knowledge of context [C] with their default response [D] of getting angry, so as to produce a practical variant $[\mathrm{V}]$ in which they retain their plan to visit 
the museum [S] but adjust its details of enactment, so as to go away and return at $3.00 \mathrm{pm}$ as suggested. (In future, when it is not Ramadan, they rely on the sign as before.)

This example introduces several new factors: mental states, culture, planning, etc. Our claim, though, is that these are details, and that the basic pattern of transduction remains the same. Both of our examples can be expressed in 'situation tables', which use the pattern of four components identified above, as follows.

Situation Table for example [E1].

[S] I have a standard route to work.

[D] I walk straight down the pavement.

[C] Today there is a big puddle across the pavement.

[V] Stop, walk round the puddle, then continue.

Situation Table for example [E2].

[S] The signs say that the museum will be open at $2.00 \mathrm{pm}$ on Wednesday, but it is not open.

[D] Get angry.

[C] This is the month of Ramadan, when Muslims have obligatory extra prayers.

[V] Go away, and come back later.

This pattern of reasoning is an addition to that identified in classical deductive logic. The pattern there is a one-step, monotonic (non-defeasible) process. That is: however complex the derivation, we deal with one set of premises and one conclusion, and introduction of new premises cannot cause retraction of a conclusion. Here we deal with two steps, $[\mathrm{S} / \mathrm{D}]$ and $[\mathrm{C} / \mathrm{V}]$, and we derive $[\mathrm{V}]$ as a version of $[\mathrm{D}]$ : not as a simple rejection of $[\mathrm{D}]$ or revision of $[\mathrm{S}]$, as identified in classical non-monotonic logic. Da Costa (1958, 1982), makes a related and illuminating point in paraconsistent logic. Da Costa's point is that inconsistency is not always a disaster. A database, for example, can be contradiction-tolerant, as is often needed in business systems. Da Costa is concerned with propositional reasoning (in which our conclusion is a statement), and we are concerned here with practical reasoning (in which our 
conclusion is an action). So we might speak here of 'contrapragma' ('against circumstances'), rather than 'contradiction' ('against speaking'). The affinity with $\mathrm{Da}$ Costa's thinking is that an opposition (whether 'contrapragma' or 'contradiction') between $[\mathrm{C}]$ and [D] may be a constructive synergy.

We attempt here to explicate constructive synergy. What is articulated is a process of working with the other. This is not a process of identifying with the other, agreeing with the other, or becoming the other. If these things come, then well and good: but they will be additions. The basic function is collaboration. In structural terms, $[\mathrm{D}]$ is changed to [V] under the influence of $[\mathrm{C}]$. We see a reasoning format here which is under new pressure in the $21 \mathrm{st}$ Century. It is normal, it is common sense, it is not new. It is basic, it does not always work, and its articulation in situation tables is useful in cross-cultural training.

\section{Discussion}

For the cross-cultural skill industry, then, we suggest that situation tables, as above, backed up by the analytical framework of transduction, with its four basic components, are useful in training. These provide a simple, graphical way of explaining cross-cultural situations, and the ways in which we succeed or fail to adjust to their circumstances.

For philosophy, in the age of BRICS, we need to abandon a model introduced by Socrates and expressed by Plato. On this model, right action (arete) is produced by right knowledge (episteme). In the early Dialogues, unsuccessful attempts are made to produce super-schemas $(\log i)$, and in the later Dialogues, these are sent to heaven as 'Platonic Forms' (eidoi) (Plato, 429-347 BCE/1997). On this model, action is determined by a single unit of knowledge. The better this unit is, the better the probability that we produce right action. In terms of schema theory, we seek super-schemas, which guarantee right action. For cross-cultural action, we might seek super-schemas which encompass all cross-cultural situations. We might develop perfect units of knowledge, which tell us what to do internationally. We could file these in a Library of Super-Schemas, thus assisting education and international understanding. Just as the Ten Commandments tell us how to act, and the 
Highway Code (DVSA, 2015) tells us how to drive, so this Library would tell us what to do in international business. Of course this is naive. We need the Ten Commandments, we need the Highway Code, we need principles and formulae: but these are subject to transduction.

Can we ever escape from transduction? Let us take a simple case: the game of 'noughts and crosses' (or 'tic-tac-toe'). As Zaslavsky (1982) explains, the game is determinate. That is: there is an algorithm for perfect play, producing a draw or win. There are 765 different positions, and 26,830 possible games. If we know this algorithm, we cannot lose. We have a super-schema. Consider, though, the situation where we are in the middle of a business deal with a person of vanity who does not like to lose any game. It might then be expedient to lose deliberately. We have a super-schema, but we modify its enactment so as to satisfy a larger purpose: getting the deal done. What this illustrates is that we cannot escape transduction, and that Socrates was wrong. However much we optimise and expand a schema, it will never be autonomously adequate to all circumstances and surprises, since these are infinite. A related point is made by Wittgenstein (1953/2009) in his 'rule-following paradox', where he recognises that, having learned a rule, the ability to 'go on' with it to new situations is something additional. We call the idealist fantasy the 'Fallacy of Completeness'. The burden of interaction entailed by globalisation may bring a welcome release from this fallacy.

We propose here a contemporary model of the relation between knowledge and action. Ideally, we would employ vast lookup tables mapping situations to facts and actions, or vast algorithms which did the same. We would employ huge but perfect formulae, there would be no need for situation-checking, and we would have the security of being right all the time. Socrates, then, would be right. Realistically, though, we are simple creatures facing a complex world, which under BRICS and other blocs has become more complex. Our cognitive resources are limited, and such an ideal strategy is not actually tenable. The point about limitation is well made by Simon $(1957,1982)$ in his treatment of bounded rationality. We therefore use a cognitive 'hack', and this hack is transduction. The old idealist model of knowledge and action is unrealistic and out-of-date. In the contemporary condition of BRICS, transduction is a necessity. 


\section{TRANSDUCTION and BRICS23}

\section{Conclusion}

This article is intended as a contribution to the theory and practice of cross-cultural skill. In theory, it replaces an idealist model of knowledge and action with a realistic and contemporary schema-based model. In practice, it provides an analytical framework, and a format of situation tables, for use in training.

\section{References}

ADLER, N.J., GunderSen, A. International Dimensions of Organizational Behavior. 5th Edition. South-Western College Publications, 2007.

ANG, S., VAN DYNE, L. (eds). Handbook of Cultural Intelligence: Theory, Measurement and Application. Routledge, 2008.

CHEW, J. "Managing MNC Expatriates through Crises: A Challenge for International Human Resource Management, Research and Practice". Human Resource Management, 12 (2), pp. 1-30, 2004.

DA CostA, N.C.A. "Nota sobre o conceito de contradição". Anuário da Sociadade Paranaense de Matemática, 1, pp. 6-8, 1958.

. "The philosophical import of paraconsistent logic". The Journal of Non-Classical Logic, 1 (1), pp. 1-19, 1982.

Driver And Vehicle Standard Agency (Dvsa). "The Official Highway Code". UK Stationery Office, 2015.

Gutemberg, P.L. "The Sino-Brazilian Principles in a Latin American and BRICS Context: The Case for Comparative Public Budgeting Legal Research". Wisconsin International Law Journal, Volume 33, No. 1, 2015.

Halverson, C. B., AQeel Tirminiz, S. (eds). Effective Multicultural Teams: Theory and Practice. Advances in Group Decision and Negotiation (Book 3). Springer, 2008.

Hofstede, G.J., Minkov, M. Cultures and Organizations: Software of the Mind, Third Edition. McGraw-Hill Education, 2010. 
LIVERMORE, D. Leading with Cultural Intelligence: The Real Secret to Success, 2nd Edition. AMACOM, 2015.

Norman, D. A., Shallice, T. "Attention to action: Willed and automatic control of behaviour". In Davidson, R. J., G. E. Schwartz, and D. Shapiro, (eds). Consciousness and Self-Regulation: Advances in Research and Theory. Plenum Press, 1986.

O'NEILL, J. "Building Better Global Economic BRICs". Global Economics Paper No: 66. Goldman Sachs, 2001.

PIAget, J. "Autobiography". In E. Boring (ed), History of Psychology in Autobiography. Clark University Press, 1952.

Plato, A. Complete Works. c. 429-347 BCE. J. M. Cooper (ed). Hackett, 1997.

SimON, H.A. Models of Man. Wiley \& Sons, 1957.

- Models of Bounded Rationality, Volumes 1 and 2. MIT Press, 1982.

WitTGenstein, L. "Philosophische Untersuchungen". Translated by G.E.M. Anscombe as Philosophical Investigations. Blackwell, 1953. Fourth edition, P. M. S. Hacker, J. Schulte (eds), Blackwell, 2009.

Zaslavsky, C. Tic Tac Toe: And Other Three-In-A Row Games from Ancient Egypt to the Modern Computer. Crowell, 1982. 